\title{
Intracranial pressure monitoring after primary decompressive craniectomy: is it useful?
}

\author{
Andreas K. Demetriades ${ }^{1}$
}

Received: 13 February 2017 / Accepted: 14 February 2017 / Published online: 27 February 2017

(C) Springer-Verlag Wien 2017

Intracranial hypertension is an important secondary insult after traumatic brain injury, and its control is considered to be of benefit to our patients. Intracranial pressure (ICP) monitoring is considered standard practice, at least in the developed world, in the modern neurosurgical management of traumatic brain injury. ICP waveform analysis and understanding has improved tremendously over the last few decades. However, there is still a lack of "class I" evidence in support of superiority of treatment based on intracranial-pressure monitoring over treatment guided by neurological testing and serial computed tomography imaging in improving short-term or longterm recovery in the general population of patients with severe traumatic brain injury [1].

In settings such as the developing world, where ICP monitoring may come with equipoise, controversies exist, including the use of postoperative ICP monitoring. As many as three consensus conferences have tried to address this and other controversies and uncertainties [2, 3, 8]. One of the recommendations was that "ICP monitoring is generally recommended following a secondary decompressive craniectomy (DC) in order to assess the effectiveness of DC, in terms of ICP control, and guide further therapy" [8].

Indeed there exists plentiful information from recent trials (DECRA and RESCUEicp) about situations where DC was employed to control rising ICP refractory to maximal medical therapy $[4,6]$; this being secondary DC.

One of the gaps in our knowledge, and the main objective of the featured study by Picetti et al. [7], was to explore the

Andreas K. Demetriades

andreas.demetriades@gmail.com

1 Department of Neurosurgery, Western General Hospital, Edinburgh, UK role of ICP monitoring in traumatic brain injury (TBI) patients after primary decompressive craniectomy. "Primary" in this context refers to DC during evacuation of an intracranial lesion in the acute phase.

Worded differently, there has been controversy as to whether ICP monitoring is futile after such primary DC.

Recent data on this topic suggest that ICP monitoring after primary DC for head-injured patients significantly decreases in-hospital mortality and should be implemented in neurocritical care to ensure the highest chances of surviving TBI [5].

Picetti et al. [7] provide further useful information on this topic. They selected and analysed data from 34 patients, out of a database of 880 . The vast majority $(26 / 34 ; 77 \%)$ were cases of acute subdural haematoma. The authors report that despite decompressive craniectomy, ICP may still rise to dangerous levels in most cases; furthermore, one-third of ICP monitoring days revealed at least one episode of intracranial hypertension. Intracranial hypertension was high enough to affect a reduction in cerebral perfusion pressure (CPP) of less than $60 \mathrm{mmHg}$ in 1-6 days monitored. Despite decompressive craniectomy, patients needed ICP- and CPP-driven escalation therapy and monitoring assistance in taking decisions.

This study is one of the first to specifically address the clinical utility of ICP monitoring after primary decompressive craniectomy.

The message is clear:

- Intracranial hypertension associated with episodes of low CPP occurs frequently after primary DC.

- This is associated with unfavourable neurological outcome; i.e. despite decompressive craniectomy, there is a correlation between ICP and poor outcome.

- The authors' results suggest that ICP monitoring is clinically useful in guiding therapy after primary (per se) DC. 


\section{References}

1. Chesnut RM, Temkin N, Carney N, Dikmen S, Rondina C, Videtta W, Petroni G, Lujan S, Pridgeon J, Barber J, Machamer J, Chaddock K, Celix JM, Cherner M, Hendrix T, Global Neurotrauma Research Group (2012) A trial of intracranial-pressure monitoring in traumatic brain injury. N Engl J Med 367(26):2471-2481

2. Chesnut R, Videtta W, Vespa P, Le Roux P (2014) Participants in the International Multidisciplinary Consensus Conference on Multimodality Monitoring. Intracranial pressure monitoring: fundamental considerations and rationale for monitoring. Neurocrit Care 21(Supp1 2):S64-S84

3. Chesnut RM, Bleck TP, Citerio G, Classen J, Cooper DJ, Coplin WM, Diringer MN, Grände PO, Hemphill JC 3rd, Hutchinson PJ, Le Roux P, Mayer SA, Menon DK, Myburgh JA, Okonkwo DO, Robertson CS, Sahuquillo J, Stocchetti N, Sung G, Temkin N, Vespa PM, Videtta W, Yonas H (2015) A consensus-based interpretation of the Benchmark Evidence from South American Trials: Treatment of Intracranial Pressure Trial. J Neurotrauma 32(22):1722-1724

4. Cooper DJ, Rosenfeld JV, Murray L, Arabi YM, Davies AR, D'Urso P, Kossmann T, Ponsford J, Seppelt I, Reilly P, Wolfe R, DECRA Trial Investigators (2011) Australian and New Zealand Intensive
Care Society Clinical Trials Group. Decompressive craniectomy in diffuse traumatic brain injury. N Engl J Med 364(16):1493-1502

5. Huang YH, Ou CY (2016) Prognostic impact of intracranial pressure monitoring after primary decompressive craniectomy for traumatic brain injury. World Neurosurg 88:59-63

6. Hutchinson PJ, Kolias AG, Timofeev IS, Corteen EA, Czosnyka M, Timothy J, Anderson I, Bulters DO, Belli A, Eynon CA, Wadley J, Mendelow AD, Mitchell PM, Wilson MH, Critchley G, Sahuquillo J, Unterberg A, Servadei F, Teasdale GM, Pickard JD, Menon DK, Murray GD, Kirkpatrick PJ, RESCUEicp Trial Collaborators (2016) Trial of decompressive craniectomy for traumatic intracranial hypertension. N Engl J Med 375(12):1119-1130

7. Picetti E, Caspani ML, Iaccarino C, Pastorello G, Salsi P, Viaroli E, Servadei F (2017) Intracranial pressure monitoring after primary decompressive craniectomy in traumatic brain injury: a clinical study. Acta Neurochir. doi:10.1007/s00701-017-3118-Z

8. Stocchetti N, Picetti E, Berardino M, Buki A, Chesnut RM, Fountas KN, Horn P, Hutchinson PJ, Iaccarino C, Kolias AG, Koskinen LO, Latronico N, Maas AI, Payen JF, Rosenthal G, Sahuquillo J, Signoretti S, Soustiel JF, Servadei F (2014) Clinical applications of intracranial pressure monitoring in traumatic brain injury: report of the Milan consensus conference. Acta Neurochir (Wien) 156(8): $1615-1622$ 